\title{
An Analysis on Spoken English at University Level Based on Production-Oriented Approach
}

\author{
Shen Li \\ Yangtze Normal University, Chongqing, China \\ Email: shenli11253@126.com
}

How to cite this paper: Li, S. (2018). An Analysis on Spoken English at University Level Based on Production-Oriented Approach. Creative Education, 9, 333-340. https://doi.org/10.4236/ce.2018.92023

Received: January 30, 2018

Accepted: February 25, 2018

Published: February 28, 2018

Copyright $\odot 2018$ by author and Scientific Research Publishing Inc. This work is licensed under the Creative Commons Attribution International License (CC BY 4.0).

http://creativecommons.org/licenses/by/4.0/

\section{(c) (i) Open Access}

\begin{abstract}
With an eye to bringing the relatively mediocre state of Chinese university students in spoken English up to a higher level, POA (Production-Oriented Approach) is closely scrutinized to measure its effect on university students in spoken English. Steps of the study include: First, two groups of students are selected, each of which is taught with either POA or PPP (Presentation, Practice, Production) in oral English lessons. Second, the level of these two groups of students is tested before and after the teaching program starts and finishes; the results of their spoken English are made into statistics and analyzed using SPSS17.0. The results are that POA and PPP performed almost equally well in improving students' accuracy of spoken English. However, POA delivered an amazing job in improving the fluency and more advanced vocabularies were used instead of simple words that primary school pupil would use. It is thus safe to conclude that POA method is conducive in boosting students' spoken English and it is of great importance to university spoken English teaching.
\end{abstract}

\section{Keywords}

POA, PPP, University English, Production Capability, Spoken English Teaching

\section{Introduction}

As one of the most widely used languages in the world, English is an important instrument that connects cultures around the world and facilitates exchanges among and between disciplines (Liu, 2016). As a required discipline for university students, it is well merited. It is a growing trend that spoken English might be included into CET4 and CET6, which have been merely written tests till today. Plans are that students can only pass CET4 or CET6 when they pass both the written part and the spoken part (Zan \& Christine, 2011). This trend is adding 
more pressure to the students and teachers to double down to improve students' spoken English. It is worth-noting here that university syllabuses have almost universally cut teaching time for English, but students are still required to complete all tasks on oral English within a limited amount of time. Therefore, efforts must be paid to improve students' oral English production capability.

POA (Production-Oriented Approach) and PPP (Presentation, Practice and Production) are two different teaching methods. PPP values more of textbooks, further squeezing opportunities for students to express their views. While in POA teaching, the pattern is that there would be an output from students, and immediately an input behind, and then an output again (Jenny \& Nancy, 2009). This output first unleashes students' stored knowledge on that subject, improving their language fluency. A majority of the studies published on POA are about theories, and empirical studies are not many (Yang \& Chang, 2008). The study conducted thereof holds great significance to empirical studies on POA. It will also help improve non-English majors' spoken English and the quality of English lectures on the whole. The study serves as a ready material for researchers to look into the impact of POA teaching to non-English majors' spoken English.

\section{Methodology}

\subsection{Experiment Targets}

The subject in the study is students from two pedestrian classes in a Chinese university. The students are of roughly the same age and taught be researchers. The class formed by students of international trade serves as the experiment group and the class from chemical engineering majors as control group. These teachings are delivered in a manner as they are used to. Since none of the students are told beforehand that an experiment is going on, so no deliberate show-off from students in the good class, avoiding Hawthorne effect (Powers \& Stansfield, 1985).

\subsection{Tools for Experiment}

The study is carried out using quantitative approach. Students from the two classes are tested before and after the methods are used. Results from the tests are marked as pre-test and post-test. To analyze results from these tests if there is an improvement made after the POA teaching method is used in teaching. The running time of the POA program is 16 weeks. Questions in the oral English tests are selected from TOEFL mock tests, ensuring the validity and reliability of these tests. The 20 minutes long speech-delivering part in the tests contains 6 questions. The former two are "independent speech making task", in which students are supposed to answer questions based on their own ideas and experiences. The remaining 4 questions are "comprehensive oral task", which requires the combined use of English listening, speaking and reading from students. Tests-takers speak into the microphone and their answers will be recorded (Gao \& Zhang, 2010). 


\subsection{Study Procedure}

Figure 1 shows the procedure of the present study.

The research process includes: drawing up teaching objectives, the settings of conversations in a certain context, the division of tasks, the evaluation of speeches by students and the audience. In the study, the test topic chosen for oral English test is about dietary conflict between the west and east. In this topic, having meals is the context of communication, and cultural conflict as the clue. The reason why this topic is chosen is that it can be applied to students of different majors, and it can test the comprehensive understanding students have acquired in their English study since they have all courses on English cultures. With the development of the economy, intercultural communication between countries is becoming increasingly more frequent, and the huge difference in the Chinese and Western food culture is one of the barriers to cross-cultural communication (Huang, 2010). Three steps are involved in Motivating part in POA teaching: the teacher makes clear the contexts in which the conversation takes place; students are required to say their views and opinions out loud with their knowledge on the topic; the objectives and tasks for the teaching are made clear by the teacher. The Enabling part consists of three parts. First, the teacher describes the production task, and then the students realize the task through selective learning. Finally, the teacher gives guidance and correction to the students' practical production. The assessment of students' classroom exercises-assessing is divided into two types: immediate assessment and a much-delayed assessment. Immediate assessment refers to the teacher's assessment in the process of choosing a learning and production task. Immediate assessment helps teachers to adjust the teaching progress, and a variety of evaluation methods can be used, such as oral report, displaying video and script. In order to check students' learning effect after class, the teacher can choose the student to answer the question randomly, and ask the group to report the presentation. Since the students do not know in advance which part of the question is asked by the teacher in the

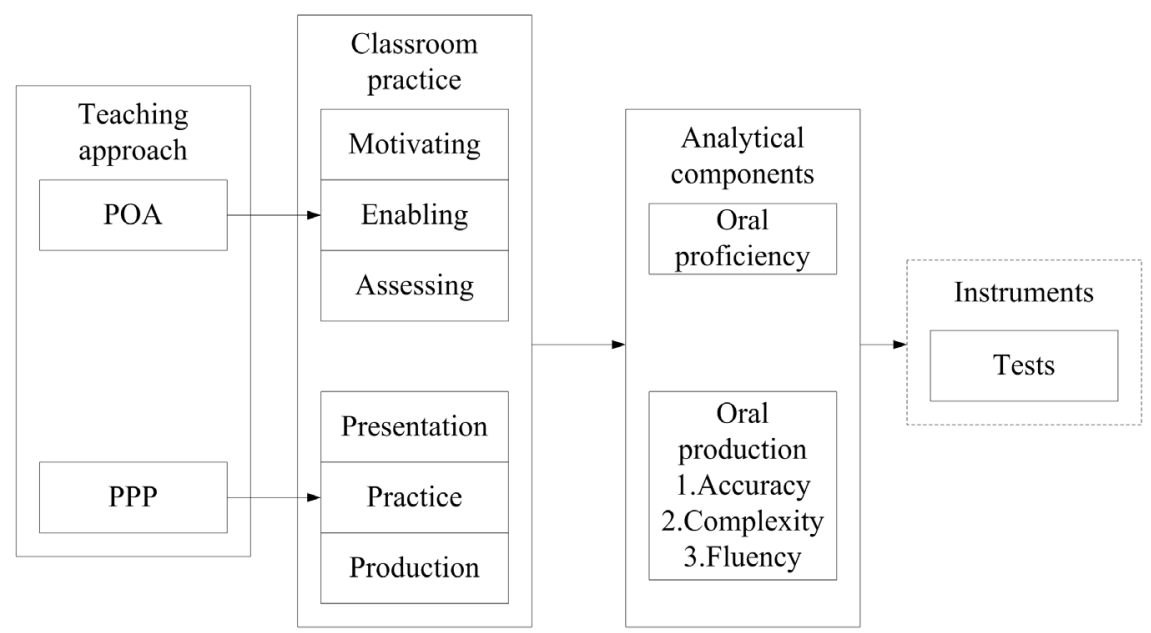

Figure 1. The procedure of the present study. 
classroom, students have to prepare for and practice extracurricular activities. For those who did not make a report or a presentation in class, they can choose to submit videos and scripts, and put them on public platform, so that viewers can browse and give feedbacks. There are two ways to evaluate the audience (students who listened the report), that is, oral and written report. One is to hand a piece of paper to each of the student audience before the report is made, and the audience should write down the content of the report. The other is to make an oral examination of what the students have learned from and understood about the report. Figure 2 is students delivering oral report in the class.

To make sure the accuracy and fairness of TOEFL spoken test, CEFR (Common European Framework of Reference) is used in the study in the grading of the test results, as shown in Table 1.

There are two ways for evaluating oral English production, namely, the overall scoring method and the analytical scoring method. The overall scoring is a comprehensive score based on the subjective evaluation criteria. This method is time-saving but not very reliable, because subjective factors may affect the

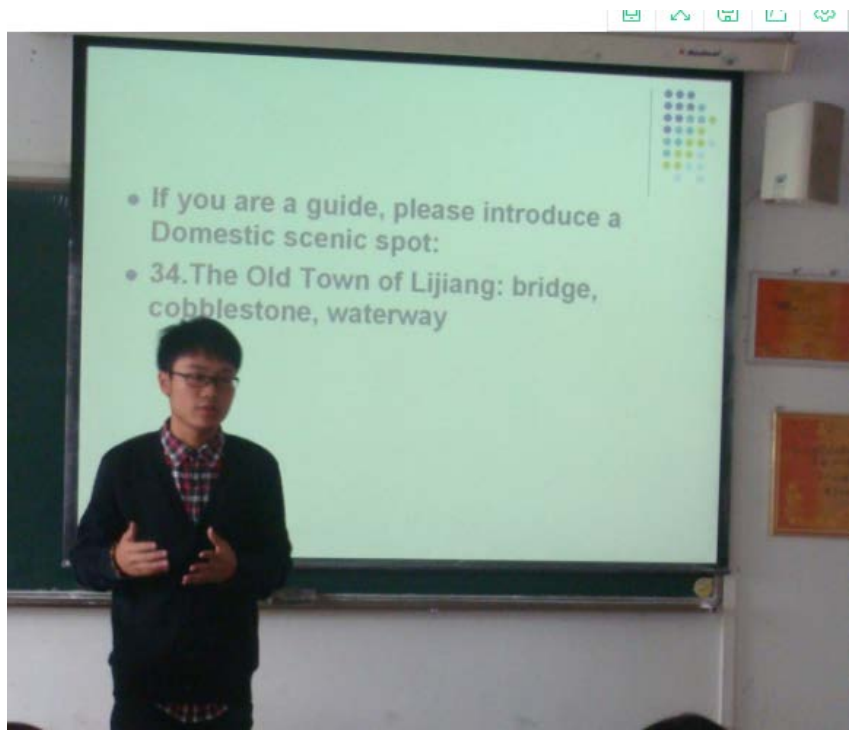

Figure 2. Students delivering oral report in class.

Table 1. The association between TOEFL iBT test scores and the common european framework of reference (CEFR) levels.

\begin{tabular}{cc}
\hline CEFR level & Speaking $(0-30)$ \\
\hline C2 & $/$ \\
C1 & 25 \\
B2 & 20 \\
B1 & 16 \\
A2 & 10 \\
A1 & 5 \\
\hline
\end{tabular}


fairness of the score. The analytical scoring method scores each task differently, which is apparently more objective and more reliable. The overall goal of oral English teaching is to cultivate the fluency, accuracy and the use of more advanced-level English words and expressions of the students' when it comes to expressing themselves in English. If these three aspects are improved, the students' oral production can be seen as improved. The three aspects of the oral test (accuracy, fluency, and the use of advanced-level English words and expressions) are measured by the following methods: accuracy is the number of error-free clauses divided by the total number of AS units, of which AS is short for analysis of speech; fluency is measured by the number of syllables uttered per minute, that is, the number of syllables per narrative is divided by the number of seconds used to complete the task, and then multiplied by 60 . Repeated words and phrases are excluded. The use of advanced-level English words and expressions is gauged by the total number of $\mathrm{T}$ units dividing the total number of independent clauses. T-units, is the total number of subordinate clause and main sub-clause with non-syntactic structures (Liu, 2013).

\subsection{Data Collection and Analysis}

Data collected in this paper are all authentic, ensuring the reliability and effectiveness of the study results. Two sets of data need to be collected for the paper, which are test results before and after the POA and PPP teaching method are carried through. The data are processed and analyzed using SPSS17.

\section{Results and Discussion}

\subsection{Results of Oral Pre-Test on Oral Proficiency}

An independent sample $t$ test is used to analyze the differences in the English production capability of the two classes. The papers cover listening, reading, writing and translation. The results of the pre-test statistics of the control group (CG, Control Group) and the experimental group (EG, Experimental Group) are as follows:

Table 2 shows that in the pre-test results, the average score of the control group is 11.90 , the standard deviation is 1.11 , while the average score of the experiment group is 11.69 , the standard deviation is 1.06 . The average scores of the two are almost the same.

Table 3 shows that $\mathrm{t}$ Sig (2-Tailed) is 0.92 , far higher than the Equality of Variance at 0.05 , so the result conforms to the assumption that the variance is equal. In other words, the difference between the experimental group and the control group is very small at the $95 \%$ confidence interval, so the levels of the two classes of students are at the same level before the experiment.

$\mathrm{N}$ of Items refers to that three people are involved in assessing the results of the pre-test (Table 4). The values of Cronbach's alpha in the control group and the experimental group were 0.98 and 0.96 , respectively, which were almost the same. Therefore, the reliability statistics of this oral pre-test are credible. 
Table 2. Statistics of oral pre-test on oral proficiency.

\begin{tabular}{ccccc}
\hline & Mean & $\mathrm{N}$ & Std. Deviation & Std. Error Mean \\
\hline EG & 11.90 & 40 & 1.11 & 0.16 \\
CG & 11.69 & 40 & 1.06 & 0.15 \\
\hline
\end{tabular}

Table 3. Independent sample t-test of oral pre-test.

\begin{tabular}{|c|c|c|c|c|c|c|c|c|c|}
\hline & \multicolumn{5}{|c|}{ Levene's Test for Equality of Variance } & \multicolumn{4}{|c|}{ T-test for Equality } \\
\hline & \multirow{2}{*}{$\mathrm{F}$} & \multirow{2}{*}{ sig } & \multirow{2}{*}{$\mathrm{t}$} & \multirow{2}{*}{$\mathrm{df}$} & \multirow{2}{*}{ Sig(2-Tailed) } & \multirow{2}{*}{$\begin{array}{c}\text { Mean } \\
\text { difference }\end{array}$} & \multirow{2}{*}{$\begin{array}{l}\text { Std Error } \\
\text { Difference }\end{array}$} & \multicolumn{2}{|c|}{$\begin{array}{l}95 \% \text { confidence Interval of } \\
\text { the difference }\end{array}$} \\
\hline & & & & & & & & lower & upper \\
\hline Pre-test Eva & 0.008 & 0.09 & 0.061 & 179 & 0.92 & 0.080 & 1.21 & -2.22 & 2.45 \\
\hline
\end{tabular}

Table 4. Reliability statistics of assessing oral pre-test.

\begin{tabular}{ccc}
\hline Reliability Statistics & Cronbach's Alpha & N of Items \\
\hline DG & 0.98 & 3 \\
EG & 0.96 & 3 \\
\hline
\end{tabular}

\subsection{Results of Oral Post-Test}

Table 5 showed that in the post-test results, the average score of the control group is 11.35 , the standard deviation is 1.09 , while the average score of the experimental group is 15.38 and the standard deviation is 0.89 . The average score of EG is much higher than that of CG, and the Std of EG is more stable than CG.

Table 6 shows that the Sig (2-Tailed) is 0.96, higher than 0.05, reflecting the uniformity of variance, so the t-test results are equal to the hypothetical variance. The significant level is 0.03 , less than 0.05 . In other words, there was a significant difference between the control group and the experimental group on the $95 \%$ confidence interval. Therefore, the students in the POA class speak much better English than the students in the PPP class, and the production capability of the two classes is not on the same level.

$\mathrm{N}$ of Items refers to that three people are involved in assessing the results of the post-test (Table 7). The values of Cronbach's alpha in the control group and the experimental group were 0.99 and 0.97 , which were almost the same. Therefore, the reliability statistics of this oral pretest are credible.

\section{Conclusion}

In the study quantitative experimental methods are deployed. The students are divided into two groups, their spoken English being taught each by the POA teaching method and the traditional PPP teaching method. Oral test before and after the experiment is taken; the questions in the oral test are found in past TOEFL exams. The results of the two oral tests are analyzed using SPSS 17 software. Before the experiment, the oral test results show that the oral production 
Table 5. Statistics of oral post-test.

\begin{tabular}{ccccc}
\hline & Mean & N & Std. Deviation & Std. Error Mean \\
\hline EG & 15.38 & 40 & 0.89 & 0.15 \\
CG & 11.35 & 40 & 1.09 & 0.18 \\
\hline
\end{tabular}

Table 6. Independent sample t-test of oral post-test.

\begin{tabular}{|c|c|c|c|c|c|c|c|c|c|}
\hline & \multicolumn{6}{|c|}{ Levene's Test for Equality of Variance } & \multicolumn{3}{|c|}{$\Gamma$-test for Equality } \\
\hline & \multirow[t]{2}{*}{$\mathrm{F}$} & \multirow[t]{2}{*}{ sig } & \multirow{2}{*}{$\mathrm{t}$} & \multirow{2}{*}{$\mathrm{df}$} & \multirow{2}{*}{ Sig (2-Tailed) } & \multirow{2}{*}{$\begin{array}{c}\text { Mean } \\
\text { difference }\end{array}$} & \multirow{2}{*}{$\begin{array}{l}\text { Std Error } \\
\text { Difference }\end{array}$} & \multicolumn{2}{|c|}{$\begin{array}{c}95 \% \text { confidence Interval of } \\
\text { the difference }\end{array}$} \\
\hline & & & & & & & & lower & upper \\
\hline Post-test Eva & 0.008 & 0.96 & 0.074 & 15 & 0.037 & 0.078 & 1.22 & -2.36 & 2.66 \\
\hline
\end{tabular}

Table 7. Reliability statistics of assessing oral post-test.

\begin{tabular}{ccc}
\hline Reliability Statistics & Cronbach's Alpha & N of Items \\
\hline DG & 0.99 & 3 \\
EG & 0.97 & 3 \\
\hline
\end{tabular}

capability of the two classes is basically the same in fluency, use of advanced words, and expressions and accuracy. The post-test results show that the POA teaching method is better than PPP in improving spoken English for non-English majors. In terms of oral production, the POA teaching method has a better effect on fluency, use of advanced words and expressions than the PPP teaching method. The two foreign language teaching models POA and PPP are basically the same in improving the accuracy of oral English.

\section{References}

Gao, Y., \& Zhang, D. (2010). Influential Factors in Oral English Learning. Asian Social Science, 6, 70-72.

Huang, L. (2010). Methods to Oral English Practice. Asian Social Science, 6, 187. https://doi.org/10.5539/ass.v6n6p187

Jenny, C., \& Nancy, J. (2009). Gender Issues in the GCSE ORAL English Examination: Part II. Language \& Education: An International Journal, 5, 261-292.

Liu, W. (2013). Role of Teachers in Oral English Teaching. Lecture Notes in Electrical Engineering, 219, 13-18. https://doi.org/10.1007/978-1-4471-4853-1_2

Liu, Y. (2016). Oral Gestural Reduction of English Nasal Coda Produced by Mandarin English-as-a-Foreign-Language Learners. Journal of the Acoustical Society of America, 140, 3339-3339. https://doi.org/10.1121/1.4970656

Powers, D. E., \& Stansfield, C. W. (1985). Testing the Oral English Proficiency of Foreign Nursing Graduates. Esp Journal, 4, 21-35. https://doi.org/10.1016/0272-2380(85)90004-6

Yang, Y. T. C., \& Chang, L. Y. (2008). No Improvement-Reflections and Suggestions on the Use of Skype to Enhance College Students' Oral English Proficiency. British Journal of Educational Technology, 39, 721-725. 
https://doi.org/10.1111/j.1467-8535.2007.00769.x

Zan, C., \& Christine, G. (2011). Teaching Oral English in Higher Education: Challenges to EFL Teachers. Teaching in Higher Education, 16, 333-345.

https://doi.org/10.1080/13562517.2010.546527 